\title{
Methyl Acrylate Derivatives as Corrosion Inhibitors for X-65 Type Carbon Steel in 1 M HCl
}

\author{
E. G. Zaki ${ }^{1, *}$, M. Abd-El-Raouf ${ }^{1, *}$, A. elaraby ${ }^{1}$, T.A. Zidan ${ }^{2}$ \\ ${ }^{1}$ Egyptian Petroleum Research Institute, Nasr City, Cairo (11727), Egypt. \\ ${ }^{2}$ Department of Polymers and Pigments, National Research Centre, 33 El Bohouth St. (former El \\ Tahrir St.), Dokki, Giza, 12622, Egypt. \\ *E-mail: abdelraouf1979@yahoo.com, chemparadise17@yahoo.com
}

doi: $10.20964 / 2021.03 .23$

Received: 30 September 2020 / Accepted: 20 November 2020 / Published: 31 January 2021

\begin{abstract}
Inhibition efficiency of prepared Methyl acrylate derivatives named 2Methacryloyloxyethyloctadecyldimethylammonium Bromide (MEODAB), poly(2Methacryloyloxyethyloctadecyldimethylammonium Bromide) (PMEODAB) for X-65 type carbon steel in $1 \mathrm{M} \mathrm{HCl}$ has been investigated by potentiodynamic polarization and electrochemical impedance spectroscopy (EIS) measurements. The prepared acrylate derivatives act as mixed-type inhibitors, which suppresses both cathodic and anodic processes by its adsorption on the electrode surface according to Langmuir adsorption isotherm, together with a slight positive shift in corrosion potential $\left(\mathrm{E}_{\text {corr }}\right)$. The inhibition efficiency IE\% reached $89.3 \%$ for compound (MEODAB) and $88.1 \%$ for compound (PMEODAB) at $150 \mathrm{ppm}$. The data obtained from electrochemical impedance spectroscopy (EIS) was analyzed to model the corrosion inhibition process through equivalent circuit. The nature of the protecting film formed on carbon steel was investigated by SEM and EDX techniques.
\end{abstract}

Keywords: Methyl acrylate derivatives, Impedance spectroscopy, Corrosion, SEM.

\section{FULL TEXT}

(C) 2021 The Authors. Published by ESG (www.electrochemsci.org). This article is an open access article distributed under the terms and conditions of the Creative Commons Attribution license (http://creativecommons.org/licenses/by/4.0/). 